\title{
Research Article \\ Study of the Thermal Properties of Raffia Bamboo Vinifera L. Arecaceae
}

\author{
E. Foadieng, ${ }^{1,2,3}$ P. K. Talla, ${ }^{2}$ G. B. Nkamgang, ${ }^{2}$ and M. Fogue ${ }^{3}$ \\ ${ }^{1}$ Higher Technical Teachers' Training College, University of Buea, Kumba, Cameroon \\ ${ }^{2}$ Laboratoire de Mécanique et de Modélisation des Systèmes Physiques, Faculty of Sciences, University of Dschang, Dschang, Cameroon \\ ${ }^{3}$ Laboratoire d'Ingénierie des Systèmes Industriels et de l'Environnement, IUT-Fotso Victor, University of Dschang, Dschang, Cameroon \\ Correspondence should be addressed to E. Foadieng; foidienge@yahoo.fr
}

Received 24 August 2016; Accepted 9 January 2017; Published 6 February 2017

Academic Editor: Fernando Lusquiños

Copyright (c) 2017 E. Foadieng et al. This is an open access article distributed under the Creative Commons Attribution License, which permits unrestricted use, distribution, and reproduction in any medium, provided the original work is properly cited.

Raffia is a kind of fast-growing palm tree, from the family of Arecaceae, encountered in marshy areas and along rivers. In this study, the "Raffia Bamboo" is the stalk of a palm, made of a fragile marrow inside a thin shell, smooth and hard to protect the latter. In our region, this material is widely used to build all the low-cost traditional houses and furniture, to make granaries storage of dry products, to build chicken coops, to make decoration. Thus, various jobs are organized around this material, with the fight against poverty. To our knowledge, information on its thermal properties is almost nonexistent. The experimental determination of the transverse thermal properties of the dry shell, the dry marrow, and the whole dry bamboo helped to find, for each, a specific heat, a thermal diffusivity, a thermal conductivity, and finally a thermal effusivity. From the analysis of results, we deduce that the thermal properties of raffia bamboo vinifera L. Arecacea make it a very good thermal insulator.

\section{Introduction}

The "raffia bamboo" is one of the oldest building materials used by man in our region. The reduction in timber reserves and the awareness of deforestation problems caused by crops have increased interest for raffia bamboos forest which are fast-growing resources [1]. The raffia palm, often underused, is present in the tropics. This is a multifunctional plant: it is solicited in the protection of the environment (water and soil conservation) and nutrition [2]; the petiole designated as "African bamboo" [3] and the raw leaves are used as building materials [4].

To our knowledge, unfortunately, there is no current study on the determination of thermal properties of raffia bamboo vinifera L. Arecaceae. Furthermore, the production and use of raffia bamboo are based solely on an ancestral know-how. Despite its apparent fragility, raffia bamboo offers a real opportunity to build among the poor who inhabit the tropical regions, because it is a cheap, abundant, and fastgrowing material that can meet the need for broad economy housing.

Some information on raffia bamboo basic properties was discussed, but the study of its thermal properties and applications as a raw material for composite products is very limited. It is an underutilized and neglected material, so that its full potential is not used. Further studies are needed to assist and promote its application in the modern world.

The optimization of properties of raffia bamboo vinifera L. Arecaceae for the development of its products requires knowledge of not only its physical properties [5] but also its thermal characteristics. In this study, we propose to evaluate the different thermal properties of raffia bamboo vinifera $\mathrm{L}$. Arecaceae.

\section{Materials and Methods}

\subsection{Materials}

2.1.1. Characteristics of the Species Studied. The raffia vinifera L. Arecaceae is in the form of a tuft is constituted of several feet, which themselves are composed of palms. A raffia palm has 4 parts: the leaflet, the spine, the petiole, and sheath basalt. The basalt sheath is the lower part of the fin characterized by more increased relative hardness. The petiole designated as "raffia bamboo" has a bright green color when fresh and gray when dry [5]. It is 5 to 10 meters high and its diameter 
varies from 2 to $10 \mathrm{~cm}$. The petiole is smooth and the leaves are opposite needles, having a parallel nervation.

Bamboo Raffia vinifera L. Arecaceae is known locally as "dink." Our samples for the study were taken from Mbieng I quarter, in the village of Bandjoun, Poumougne Subdivision, Koung-Khi Division, Western Region Cameroon. Mbieng I is located at $5^{\circ} 25$ north latitude, $10^{\circ} 25$ longitude, and 1509 meters above sea level.

2.1.2. Test-Tube Preparation. On each test-tube of marrow or shell, we have prepared a smooth flat surface that will be exposed to energy flash. The probe of the thermohygrometer is inserted into the test-tube at $2 \mathrm{~mm}$ behind said surface for obtaining the temperature variations and to be simultaneously protected from the heat exchange by convection with the laboratory air. This arrangement allows the probe to be in agreement with the model of Parker where the specimen thickness (distance between front and back) is $2 \mathrm{~mm}$.

The test-tubes used for testing have a size of $20 \times 20$ $\times 40 \mathrm{~mm}^{3}$ for the marrow, $2 \times 20 \times 40 \mathrm{~mm}^{3}$ for the shell, and $h=d / 2$ for the whole bamboo, taking in account the size of our calorimeter. About $120 \mathrm{ml}$ of water is weighed by a brand OHAUS balance (FLORHAM PARK) precision $1 / 10$ and placed in a Leybold-Heraeus Calorimeter brand of German manufacture and heat capacity $66 \mathrm{Jk}^{-1}$ with a thermometer precision of $1 / 10$. The content of the latter is at the laboratory temperature close to $24^{\circ} \mathrm{C}$. After a stay of 72 hours in an oven set to $100^{\circ} \mathrm{C}$ the test-tubes are weighed by Mettler AE160 electronic balance of $10^{-6}$ precision and reintroduced into the oven.

\subsection{Methods}

2.2.1. Specific Heat. The selected method of measuring the specific heat capacity or specific heat is known as calorimetric method [6].

After 24 hours, the test-tube is immediately taken out from the oven and added to the contents of the calorimeter [7]. Following the exchange of heat, the maximum temperature $T_{m}$ of the calorimeter content is reached after a time $t_{1} . T_{m}$ is similar to the contents temperature at thermal equilibrium when the calorimeter is perfectly adiabatic.

(1) Method Principle. A sample heated for at least 24 hours in an oven set at $100^{\circ} \mathrm{C}$ is immersed in water of the preceding calorimeter. One detects the maximum temperature reached by the water of the calorimeter. The heat balance between the initial time $t_{0}=0$ corresponding to the introduction of the solid sample in the calorimeter [8] and time $t$ corresponding to the maximum temperature [9] reached by the water of the calorimeter is

$$
\begin{aligned}
m_{S} C_{S}\left(T_{S i}-T_{e \text { moy }}\right)= & C_{e}\left(m_{e+} \mu_{e}\right)\left(T_{e \max }-T_{e i}\right) \\
& +\int_{0}^{t} U S\left(T_{e \text { moy }}-T_{a}\right) d t,
\end{aligned}
$$

where $T_{S i}$ the initial temperature of the specimen, $T_{e \max }$ is the maximum temperature of the water, $T_{e \text { moy }}$ is the average water temperature, $T_{e i}$ is the initial temperature of the water, and $T_{a}$ is the ambient temperature of the experimental room.

We deduce the specific heat capacity $C_{S}$ of the sample in $\mathrm{J} / \mathrm{kg} \cdot{ }^{\circ} \mathrm{C}$ :

$$
\begin{aligned}
C_{S} & =\frac{1}{m_{S}\left(T_{S i}-T_{e \max }\right)}\left[C_{e} \cdot\left(m_{e+} \mu_{c}\right)\left(T_{e \max }-T_{e i}\right)\right. \\
& \left.+\int_{0}^{t} U S \cdot\left(T_{e \text { moy }}-T_{a}\right) d t\right],
\end{aligned}
$$

where $m_{e}$ is the mass of water, $\mu_{c}$ is the water equivalent of the calorimeter and its accessories, $U$ is the overall heat loss coefficient, and $S$ is the heat exchange surface.

(2) Determination of Overall Heat Loss Coefficient. One pours mass $m$ of hot water at temperature $T_{e i}$ in a calorimeter in thermal equilibrium with the laboratory room which is at temperature $T_{a}$. Whole water calorimeter reaches thermal equilibrium at temperature $T_{\mathrm{eq}}<T_{e i}$. The variation of the water temperature is due to thermal losses because the calorimeter's water exchanges heat with the laboratory by convection, conduction, and radiation. If $T_{e}$ is the temperature of the water at a later time, the heat balance which results can be written as follows:

$$
U\left(T_{e}-T_{a}\right)=-m_{e} C_{e} \frac{d T_{e}}{d t},
$$

where $U$ is the overall coefficient of heat loss, $m_{e}$ is the mass of water, and $C_{e}$ is the specific heat of water.

During the experiment, the laboratory temperature is practically constant. The integration of (3) gives time $t$ :

$$
\ln \left(\frac{T_{e}(t)-T_{a}}{T_{e i}-T_{a}}\right)=-\frac{U}{m_{e} C_{e}} t
$$

Slope $a_{t}$ of the straight line $\ln \left(\left(T_{e}(t)-T_{a}\right) /\left(T_{e i}-T_{a}\right)\right)=f(t)$ is used to calculate $U$ coefficient:

$$
\begin{aligned}
& a_{t}=-\frac{U}{m_{e} C_{e} C_{e}}, \\
& U=m_{e} C_{e} C_{e} \cdot a_{t} .
\end{aligned}
$$

(3) Determination of the Water Equivalent of the Calorimeter. One pours hot water of mass $m_{e c}$ at temperature $T_{e c}$ in a calorimeter containing cold water of mass $m_{e f}$ at the temperature $T_{e f}$. If $T_{e \max }$ is the maximum temperature reached by the mixture, the heat balance gives

$$
\left(m_{e f}+\mu_{C}\right)\left(T_{e \max }+T_{e f}\right)=m_{e c}\left(T_{e c}+T_{e \max }\right) .
$$

Here the heat losses are neglected because the experience is so fast that one can admit that the heat exchange between the calorimeter and the laboratory is practically negligible. We can deduce the following:

$$
\mu_{c}=m_{e c} \frac{T_{e c}-T_{e \max }}{T_{e \max }-T_{e f}}-m_{e f} .
$$




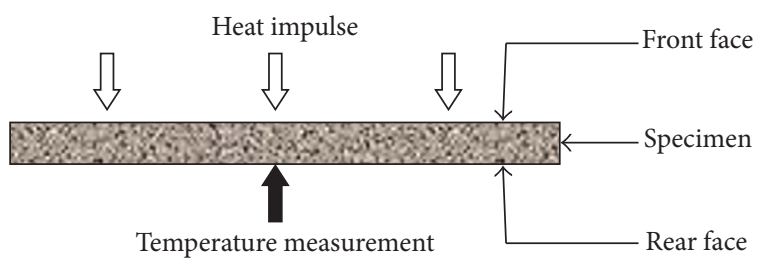

FIGURE 1: Principle of the flash methodology and implementation.

(4) Determination of the Specific Heat of a Wet Material. The specific heat of the dry test-tube is known; one can determine specific heat $C$ of the specimen having a known moisture content. If we neglect the voluminal heat of air and water vapor compared with the liquid and solid phases, we have

$$
\rho C=\rho_{0}\left(C_{S}+C_{e} H\right)
$$

knowing that

$$
\begin{aligned}
\rho & =\rho_{0}(1+H), \\
H & =\frac{m_{e}}{m_{S}}
\end{aligned}
$$

specific heat of wet specimen is deduced by

$$
C=\frac{m_{S} C_{S}+m_{e} C_{e}}{m_{H}}
$$

where $\rho_{0}$ is density of dry specimen, $m_{e}$ is the mass of water contained in the specimen, $m_{s}$ is the mass of anhydrous specimen, $m_{H}$ is the mass of the wet specimen, $C_{e}$ is the specific heat of water, and $C_{S}$ is the specific heat of the dry sample.

2.2.2. Thermal Diffusivity. The process uses flash method, in transient regimen. On each specimen, a flat and smooth surface was made, covered with silicone grease, which limits the loss of energy during the heat transfer. This surface was briefly (about 30 seconds) contacting a hot plate hydraulic press EMCO brand of American manufacturing.

The temperature sensor of an electronic thermohygrometer, ETHG913R model Oregon Scientific, was introduced in the test-tube, $2 \mathrm{~mm}$ from the flat surface as Parker and Degiovanni models (Figure 2) to minimize heat exchange with the environment. Ten raffia bamboo samples were used for the experiments.

Principle of Plate Flash Method. The principle of the method (Figure 1) is to apply a more or less localized thermal perturbation in time and space (short flow of heat provided by a flash tube, a laser, a resistor, etc.) on the front of a testtube and to measure, on the back, the change in temperature with respect to time. Thus, we establish the thermogram of the material. From this thermogram, the thermal diffusivity of the specimen is determined.

One of the main difficulties of the method is the consideration of heat loss by radiation and natural convection. Many techniques have been proposed to determine the thermal diffusivity of a specimen comparing the experimental thermogram with a theoretical thermogram from a model [10-18].

Thermogram of the Rear Panel. In the ideal case it is assumed that the thermal energy of the pulse is instantaneous and uniformly distributed on the front face of the sample with a surface density $Q$. The studied material is assumed to be homogeneous, isotropic, and opaque; these thermal characteristics are assumed to be constant with temperature, at least under the conditions of the experiment; one considers that the heat losses of different faces are void; we denote by e the sample thickness and by $\boldsymbol{\alpha}$ the thermal diffusivity [11].

The resolution of the heat equation, whose the solution is easily obtained in this case using the Laplace transform, leads to the expression of temperature variations on the rear face of the material and given as [10]

$$
T(e, t)=T_{m}\left[1+2 \sum_{n=1}^{\infty}(-1)^{n} \exp \left(-\frac{n^{2} \pi^{2} \alpha}{e^{2}} t\right)\right],
$$

where $T_{m}$ is the maximum value of the temperature reached by the rear face.

Pradhan et al. [9] proposed to determine the thermal diffusion from the time $t_{1 / 2}$ which is the time required for the temperature $T\left(e, t_{1 / 2}\right)$ to become $T_{m} / 2$.

Expression (11) then leads to

$$
\alpha=\frac{1.39 e^{2}}{\pi^{2} t_{1 / 2}} .
$$

In this ideal case, the unique measurements of the thickness $e$ of the sample and the time of half rise thermogram thus allow the determination of the thermal diffusivity [14]. In particular, it is not necessary to know the density per unit area $Q$ energy absorbed by the sample. This quantity can be calculated if one knows the product value $\rho C$ where $\rho$ is the density of the sample and $C$ its specific heat capacity. [10] Then

$$
Q=\rho C e T_{m}
$$

Conversely, if we know the amount of energy absorbed $Q$ and $T_{m}$, the value of $\rho \mathrm{C}$ and hence the thermal conductivity can be deduced.

Thermogram of the Front Face. The evolution of the temperature on the front face is given by

$$
T(0, t)=T_{m}\left[1+2 \sum_{n=1}^{\infty} \exp \left(-\frac{n^{2} \pi^{2} \alpha}{e^{2}} t\right)\right] .
$$

For small values of $t$, the sample has been similar to a semiinfinite wall and the temperature is expressed as

$$
T(0, t) \approx \frac{T_{m} \cdot e}{(\pi \alpha t)^{1 / 2}} .
$$

If one knows the energy density $Q$ absorbed, one can deduce the thermal effusivity. 


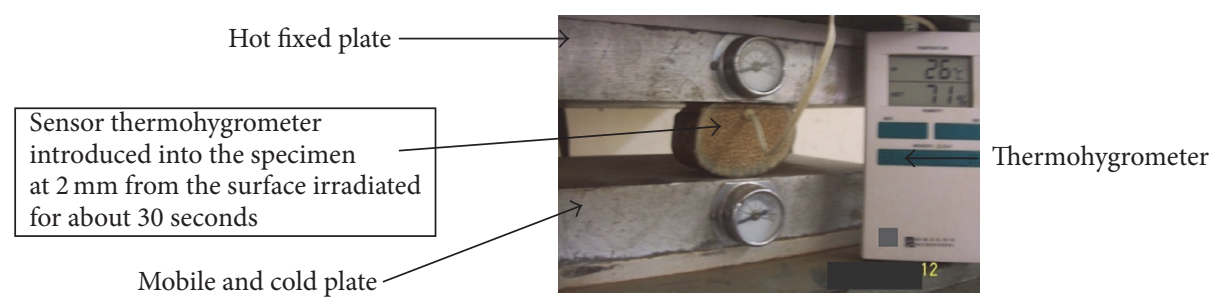

FiguRe 2: Thermal flash tester.

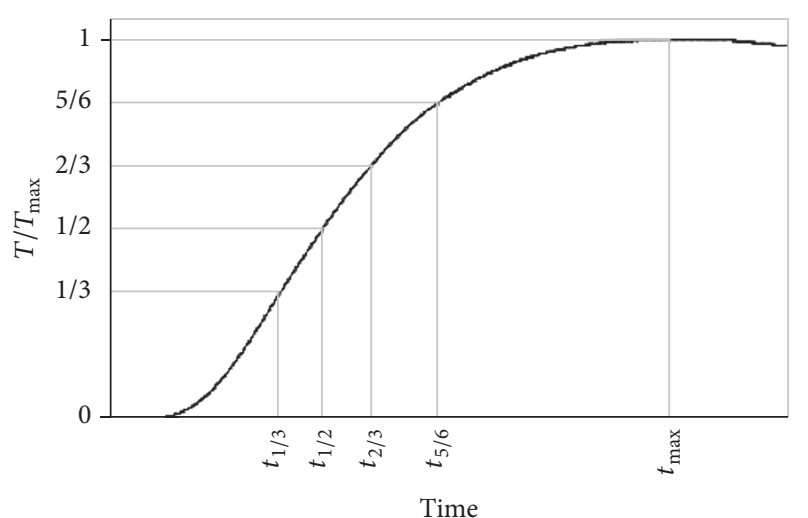

FIgURe 3: Definition of times, $t_{1 / 3}, t_{1 / 2}, t_{2 / 3}, t_{5 / 6}$ and $t_{\max }$, used in Parker and Degiovanni models.

\section{Analytical Models Used for the Determination of Thermal Diffusivity}

(1) Parker Model. This model is to consider a perfectly isolated disc of thickness $e$ of about $2 \mathrm{~mm}$ and of radius $R$. Initially, the sample receives an energy pulse of very short duration [19]; the heat absorption occurs on the surface uniformly [14]. Exchange coefficients are assumed to be zero on all sides and the heat flux propagates parallel to the optical axis [20] (Astm STP 885). The temperature of the rear side, expressed in reduced coordinates, is given by

$$
T^{*}(e, t)=1+2 \sum_{n}^{\infty}(-1)^{n} \exp \left(-n^{2} \Omega\right)
$$

where $n$ is whole number, $e$ is the thickness of the sample, $t$ is the time, and $\Omega$ and $T^{*}$ are time and reduced temperature and are, respectively, defined by the following relationships:

$$
\begin{aligned}
T^{*}(e, t) & =\frac{T(e, t)-T_{0}}{T_{\max }-T_{0}}, \\
\Omega & =\frac{\pi^{2} \cdot \alpha \cdot t}{e^{2}},
\end{aligned}
$$

where $T_{0}$ is the initial temperature and $T_{\max }$ is the maximum temperature.

The diffusivity is then obtained from the thickness of the sample and the half rise $\left(t_{1 / 2}\right)$, that is to say the time necessary for the temperature to be equal to $T_{\max } / 2$ (Figure 3 ).
The thermal diffusivity $\alpha$ is obtained by

$$
\alpha=0.139 \times \frac{e^{2}}{t_{1 / 2}}\left(\mathrm{~m}^{2} \cdot \mathrm{s}^{-1}\right),
$$

where $e$ is the thickness of the specimen and $t_{1 / 2}$ is the time at which the temperature of the rear face of the specimen is the half of its maximum elevation reached.

(2) Degiovanni Model. The heat losses by the various faces of the sample mean that the maximum temperature on the rear is lower than in the ideal case considered by the model of Parker. It overestimates the diffusivity of the material. Degiovanni model, on the contrary, takes into account the losses by introducing heat exchange coefficients on the upper, lower, and lateral surfaces [18]. The diffusivity is then calculated from equations (20). As part of this study, presented conductivities are those obtained by the analysis.

$$
\begin{aligned}
& \alpha_{1 / 3} \\
& =\frac{e^{2}}{t_{5 / 6}}\left[0.8498-1.8451 \frac{t_{1 / 3}}{t_{5 / 6}}+1.0315\left(\frac{t_{1 / 3}}{t_{6 / 6}}\right)^{2}\right], \\
& \alpha_{1 / 2}=\frac{e^{2}}{t_{5 / 6}}\left[0.968-1.6382 \frac{t_{1 / 2}}{t_{5 / 6}}+0.6148\left(\frac{t_{1 / 2}}{t_{5 / 6}}\right)^{2}\right], \\
& \alpha_{2 / 3} \\
& =\frac{e^{2}}{t_{5 / 6}}\left[5.1365-11.9554 \frac{t_{2 / 3}}{t_{5 / 6}}+7.1793\left(\frac{t_{2 / 3}}{t_{5 / 6}}\right)^{2}\right],
\end{aligned}
$$

where $t_{i}=t_{1 / 3}, t_{1 / 2}, t_{2 / 3}$, and $t_{5 / 6}$ (Figure 2) is the time at which the temperature of the rear rises $i$ time its maximum elevation reached $\left(T_{\max } / 3, T_{\max } / 2,2 T_{\max } / 3,5 T_{\max } / 6\right)$.

In practice we note that the value of the diffusivity is

$$
\alpha=\frac{1}{3}\left(\alpha_{1 / 3}+\alpha_{1 / 2}+\alpha_{2 / 3}\right) .
$$

The application of this method to test pieces of wood was used to determine their thermal diffusivity and thermal conductivities in the direction perpendicular to the fiber [15].

\subsubsection{Conductivity and Thermal Effusivity in the Direction} Perpendicular to the Fiber. These two parameters are derived from thermal diffusivity and experimental formulas that relate to the mass density [21]. 


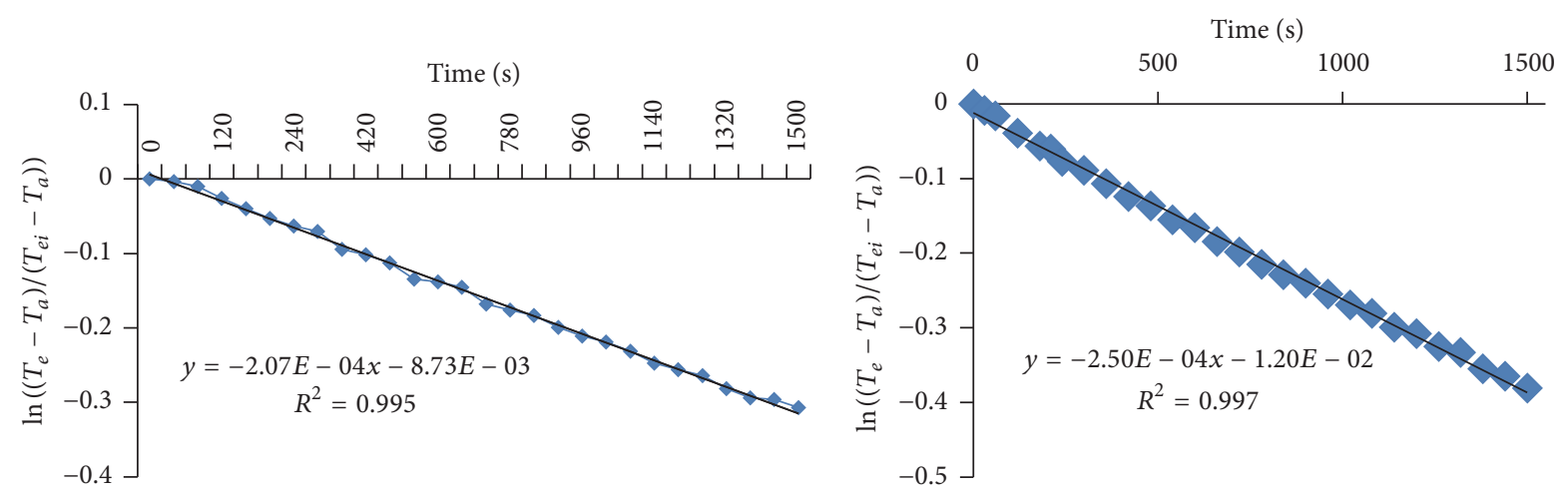

FIGURE 4: Graphic determination of the overall coefficient of heat loss calorimeter.
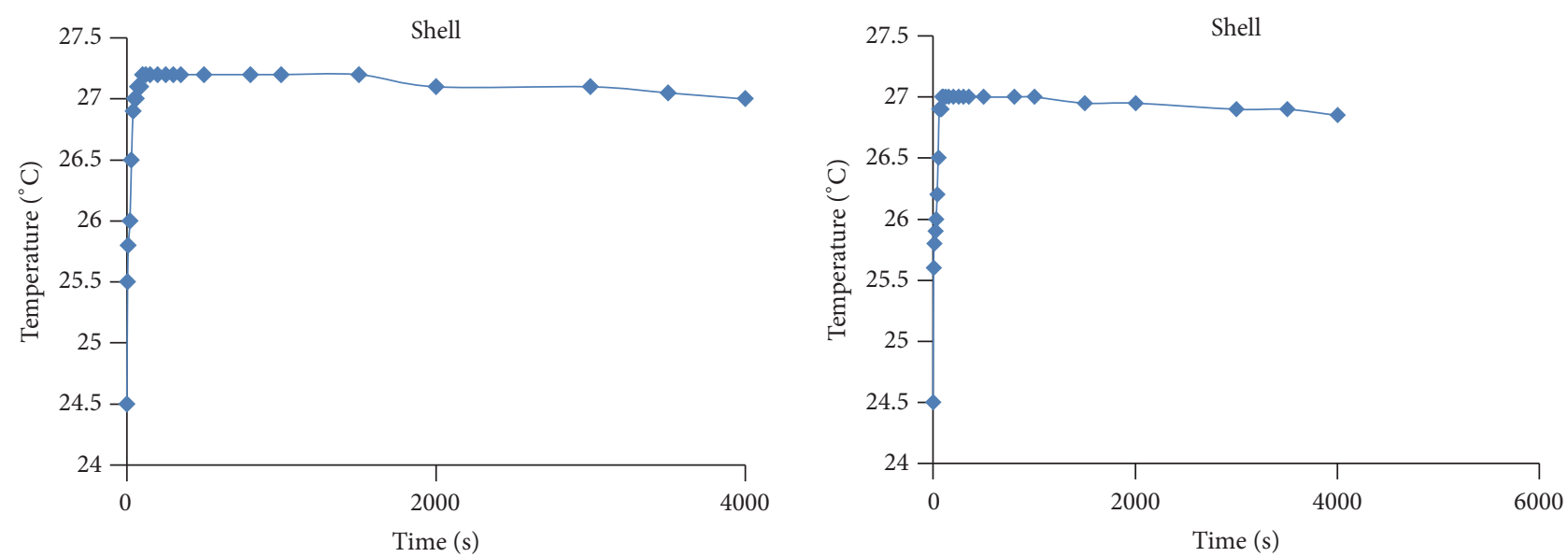

FIGURE 5: Variation of the water temperature of the calorimeter after the introduction of the hot shell.

TABLE 1: Experimental values of the overall heat loss coefficient.

\begin{tabular}{lccc}
\hline Test-tube & $M(\mathrm{~g})$ & $a_{t}$ & $U\left(\mathrm{~W} / \mathrm{m}^{2} \mathrm{~K}\right)$ \\
\hline $\mathrm{N}^{\circ} 1$ & 276.32 & $2.07 E-04$ & 0.239 \\
$\mathrm{~N}^{\circ} 2$ & 211.14 & $2.50 E-04$ & 0.221 \\
$\mathrm{~N}^{\circ} 3$ & 245.23 & $2.34 E-04$ & 0.240 \\
$\mathrm{~N}^{\circ} 4$ & 255.76 & $2.17 E-04$ & 0.232 \\
\hline Average & & 0.233 \\
Standard deviation & & 0.009 \\
\hline
\end{tabular}

\section{Results}

3.1. Specific Heat Capacity. A series of 10 measurements allowed us to estimate the average experimental value of the "water equivalence" of the calorimeter and accessories equal to $16.72 \mathrm{~g}$, as well as the overall heat loss coefficient (Figure 4).

By linear regression analysis applied to the curves in Figure 4 we determined the slope $a_{t}$ of the curve $\ln \left(\left(T_{e}(t)-\right.\right.$ $\left.\left.T_{a}\right) /\left(T_{e 0}-T_{a}\right)\right)=f(t)$ which allowed us to calculate the overall heat loss coefficient $U$ according to (5). Its average value is $0.233 \mathrm{~W} / \mathrm{m}^{2} \mathrm{~K}$ knowing that the heat exchange surface $S$ is equal to $0.03181 \mathrm{~m}^{2}$. The results are summarized in Table 1. The high value of the correlation coefficient $R^{2}>$ 0.99 allows us to believe that we are close to the good result.
After introduction into the calorimeter the anhydrous specimen was immediately removed from the oven and the temperature of the water of the calorimeter increases and reaches a maximum value. The curves (Figure 5) show changes in the temperature of the water and are used to identify the temperature values needed to determine the specific heat of each sample. The results are shown in Tables 3 , 4 , and 5 where each value is the average of 10 measurements. Specific heat obtained is that for anhydrous specimen.

3.2. Thermal Diffusivity, Thermal Conductivity, and Thermal Effusivity of Marrow and Shell. During testing, we found that excitation time of 30 seconds is sufficient to achieve a significant rise in the temperature of a point in the plane located $2 \mathrm{~mm}$ from the irradiated side (Figure 9). Experimental data have allowed us to represent thermograms of such a plan on 10 specimens. Two of the obtained thermograms are shown in Figure 6.

Each $t_{i}$ value is determined through a correlation obtained by plotting a curve of time with respect to the temperature rise. Two examples of these curves are shown in Figure 7.

The different values of time $t_{i}$ deducted allowed us to represent $T / T_{\max }$ over time. The shape of the curves in Figure 8 is in agreement with the model of Parker and 

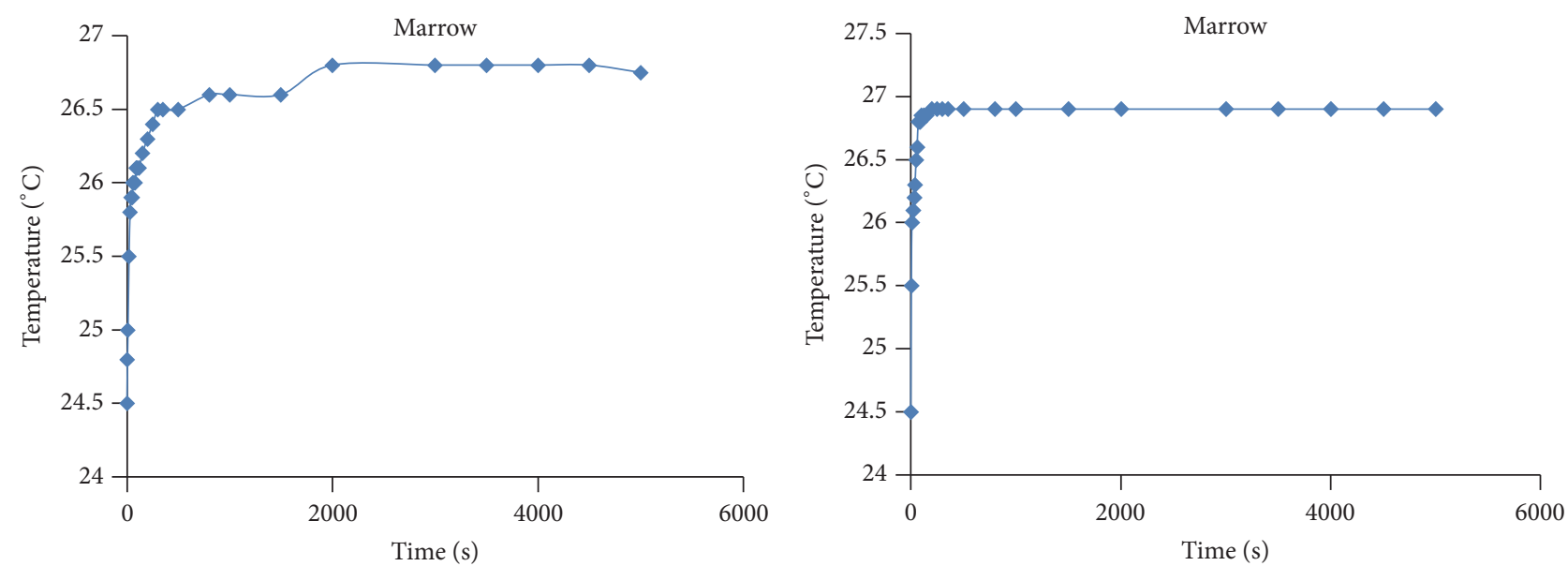

FIGURE 6: Variation of the water temperature of the calorimeter after the introduction of the hot marrow.
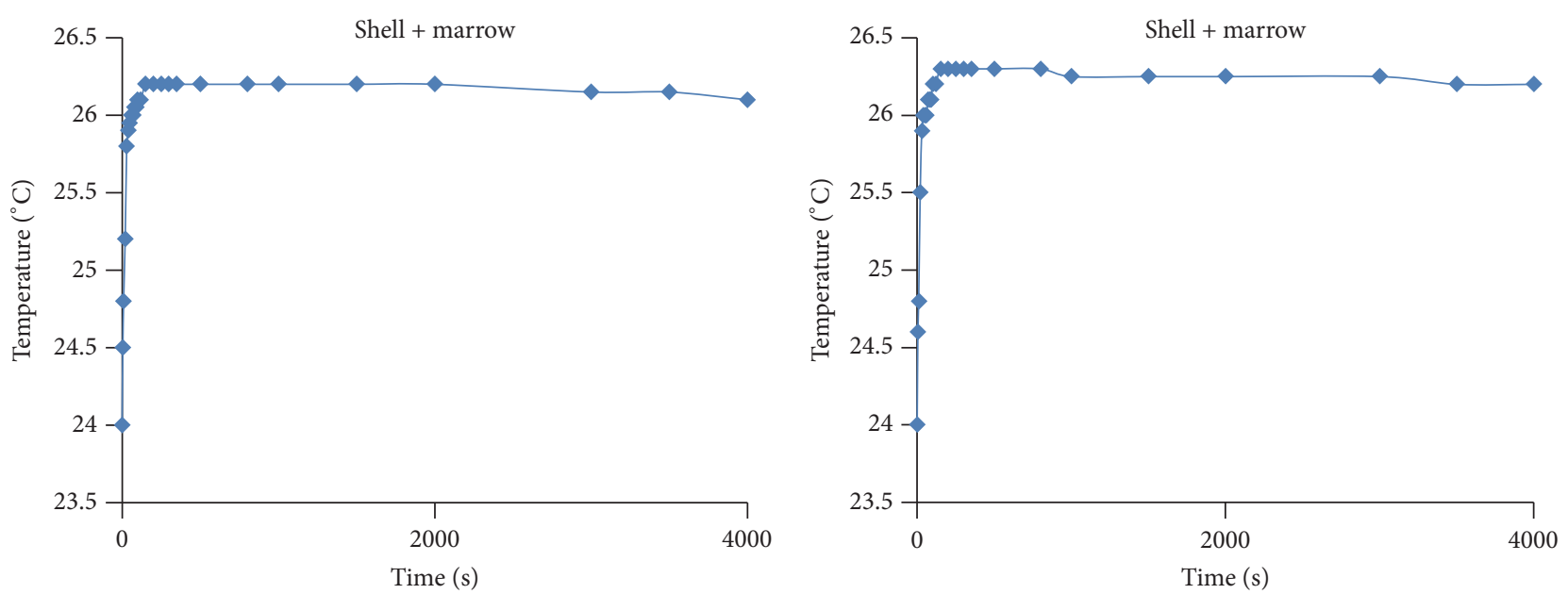

FIGURE 7: Variation of the water temperature of the calorimeter after the introduction of hot bamboo.

Degiovanni. This allows us to exploit this analytical model to determine the thermal diffusivity of raffia bamboo.

The approximate values of the thermal diffusivity $\alpha_{\exp }$ are estimated using the formulas of Parker and Degiovanni model ((17), (18), and (19)) (Figure 10). Knowing the experimental values of the specific heat $C_{\exp }$ we deduce those of the thermal conductivity $\lambda_{\exp }$ and effusivity $E_{\exp }$ from (21). Formulas (18) and (21) in the literature allow us to calculate the theoretical thermal conductivity $\lambda_{\text {theo }}$ in the transverse direction to the fiber in order to deduce the thermal diffusivity $\alpha_{\text {theo }}$ and theoretical thermal effusivity $E_{\text {theo }}$.

The moisture content values and densities are summarized in Table 2. The experimental average values of thermal properties, compared with the values obtained using the theoretical formulas, are grouped in Tables 3, 4, and 6.

\subsection{Thermal Properties of Transverse Bamboo Raffia Vinifera.}

The basics of physical properties are summarized in Table 5. Knowing the experimental values of the heat capacity and density, we evaluated the values of the transverse thermal
TABLE 2: Moisture content and density of different specimens.

\begin{tabular}{lcccccc}
\hline Specimen & \multicolumn{3}{c}{ Shell } & \multicolumn{3}{c}{ Marrow } \\
& $H \%$ & $d_{a}$ & $d_{H}$ & $H \%$ & $d_{a}$ & $d_{H}$ \\
$\mathrm{~A}$ & 13.31 & 0.79 & 0.65 & 13.92 & 0.174 & 0.124 \\
$\mathrm{~B}$ & 14.34 & 0.71 & 0.58 & 13.37 & 0.127 & 0.069 \\
$\mathrm{C}$ & 12.44 & 0.78 & 0.63 & 14.33 & 0.222 & 0.175 \\
$\mathrm{D}$ & 13.22 & 0.97 & 0.92 & 14.04 & 0.231 & 0.187 \\
$\mathrm{E}$ & 11.57 & 0.91 & 0.83 & 13.76 & 0.159 & 0.113 \\
$\mathrm{~F}$ & 13.36 & 0.98 & 0.81 & 13.07 & 0.179 & 0.129 \\
$\mathrm{G}$ & 14.33 & 0.78 & 0.68 & 13.36 & 0.207 & 0.135 \\
$\mathrm{H}$ & 12.14 & 0.86 & 0.71 & 13.82 & 0.125 & 0.095 \\
$\mathrm{I}$ & 12.47 & 0.8 & 0.66 & 12.92 & 0.173 & 0.137 \\
$\mathrm{~J}$ & 12.28 & 0.83 & 0.68 & 14.71 & 0.189 & 0.145 \\
\hline Average & 12.95 & 0.84 & 0.72 & 13.73 & 0.1786 & 0.1309 \\
Standard deviation & 0.925 & 0.09 & 0.10 & 0.559 & 0.036 & 0.035 \\
\hline
\end{tabular}

conductivity, thermal diffusivity, and the thermal effusivity presented in the Table 3 by using of relations ((14) and (21)). 
TABLE 3: Thermal capacity, diffusivity, conductivity, and effusivity of the shell of raffia bamboo.

\begin{tabular}{|c|c|c|c|c|c|c|c|c|}
\hline & Specimen & $\begin{array}{c}C_{\text {Sexp }} \\
(\mathrm{J} / \mathrm{kg} \cdot \mathrm{K})\end{array}$ & $\begin{array}{c}\lambda_{c a} \\
(\mathrm{~W} / \mathrm{m} \cdot \mathrm{K})\end{array}$ & $\lambda_{\text {théo }}$ & $\begin{array}{c}\alpha_{\exp } \times 10^{-8} \\
\left(\mathrm{~m}^{2} / \mathrm{s}\right)\end{array}$ & $\alpha_{\text {theo }} \times 10^{-8}$ & $\begin{array}{c}E_{f c a} \\
\left(\mathrm{~J} \cdot \mathrm{s}^{1 / 2} / \mathrm{K} \cdot \mathrm{m}^{2}\right)\end{array}$ & $E_{f \text { theo }}$ \\
\hline \multirow{10}{*}{ Shell } & $\mathrm{A}$ & 7833.5 & 0.15 & 0.17 & 2.37 & 2.69 & 963.5 & 930.4 \\
\hline & B & 6964.0 & 0.10 & 0.15 & 2.06 & 2.07 & 703.2 & 778.4 \\
\hline & $\mathrm{C}$ & 7178.2 & 0.12 & 0.16 & 2.13 & 2.94 & 819.7 & 850.6 \\
\hline & $\mathrm{D}$ & 8822.2 & 0.18 & 0.2 & 2.44 & 2.35 & 1241.1 & 1274.1 \\
\hline & $\mathrm{E}$ & 7323.8 & 0.14 & 0.19 & 2.17 & 2.81 & 965.9 & 1074.7 \\
\hline & $\mathrm{F}$ & 6836.2 & 0.12 & 0.2 & 1.76 & 2.07 & 896.6 & 1052.4 \\
\hline & G & 6286.7 & 0.12 & 0.16 & 2.40 & 2.19 & 767.1 & 827.0 \\
\hline & $\mathrm{H}$ & 7642.4 & 0.14 & 0.18 & 2.16 & 2.47 & 959.2 & 988.3 \\
\hline & I & 7580.8 & 0.12 & 0.17 & 2.07 & 2.33 & 853.1 & 922.3 \\
\hline & $\mathrm{J}$ & 6557.7 & 0.11 & 0.17 & 1.96 & 2.87 & 773.8 & 870.7 \\
\hline & Average & 7302.60 & 0.15 & 0.17 & 2.35 & 2.58 & 894.30 & 956.90 \\
\hline & Standard deviation & 724.10 & 0.08 & 0.02 & 0.76 & 0.34 & 152.40 & 146.80 \\
\hline
\end{tabular}

TABLE 4: Thermal capacity, diffusivity, conductivity, and effusivity of anhydrous marrow of raffia bamboo.

\begin{tabular}{|c|c|c|c|c|c|c|c|c|}
\hline & Specimen & $\begin{array}{c}C_{\text {Sexp }} \\
(\mathrm{J} / \mathrm{kg} \cdot \mathrm{K})\end{array}$ & $\lambda_{c a}(\mathrm{~W} / \mathrm{m} \cdot \mathrm{K})$ & $\lambda_{\text {théo }}$ & $\begin{array}{c}\alpha_{\exp } \times 10^{-8} \\
\left(\mathrm{~m}^{2} / \mathrm{s}\right)\end{array}$ & $\alpha_{\text {theo }} \times 10^{-8}$ & $\begin{array}{c}E_{f c a} \\
\left(\mathrm{~J} \cdot \mathrm{s}^{1 / 2} / \mathrm{K} \cdot \mathrm{m}^{2}\right)\end{array}$ & $E_{f \text { thec }}$ \\
\hline \multirow{12}{*}{ Marrow } & A & 13761.0 & 0.042 & 0.05 & 1.72 & 1.71 & 317.1 & 346.0 \\
\hline & B & 15474.2 & 0.049 & 0.041 & 2.47 & 2.09 & 310.3 & 283.9 \\
\hline & $\mathrm{C}$ & 12643.1 & 0.051 & 0.059 & 1.83 & 2.09 & 378.3 & 407.0 \\
\hline & $\mathrm{D}$ & 10666.3 & 0.043 & 0.06 & 1.74 & 2.43 & 325.5 & 384.5 \\
\hline & $\mathrm{E}$ & 17893.7 & 0.047 & 0.047 & 1.66 & 1.67 & 365.7 & 365.7 \\
\hline & $\mathrm{F}$ & 11167.5 & 0.043 & 0.051 & 2.17 & 1.89 & 293.2 & 319.3 \\
\hline & G & 13771.7 & 0.049 & 0.056 & 1.72 & 1.57 & 373.7 & 399.6 \\
\hline & $\mathrm{H}$ & 13623.1 & 0.038 & 0.041 & 2.23 & 1.99 & 254.4 & 264.2 \\
\hline & I & 12242.4 & 0.038 & 0.05 & 1.80 & 1.82 & 283.7 & 325.4 \\
\hline & $\mathrm{J}$ & 12877.0 & 0.055 & 0.053 & 2.27 & 1.79 & 365.9 & 359.2 \\
\hline & Average & 13412.0 & 0.046 & 0.051 & 1.96 & $1.91 E-08$ & 326.8 & 345.5 \\
\hline & $\begin{array}{l}\text { Standard } \\
\text { deviation }\end{array}$ & 2093.8 & 0.006 & 0.007 & 0.29 & 0.25 & 42.8 & 47.5 \\
\hline
\end{tabular}

TABLE 5: Moisture content and densities of raffia bamboo for the tests.

\begin{tabular}{ccccccc}
\hline & Specimen & $m_{H}(\mathrm{~g})$ & $m_{a}(\mathrm{~g})$ & $H \%$ & $d_{a}$ & $d_{H}$ \\
\hline \multirow{4}{*}{ Raffia bamboo } & $\mathrm{A}$ & 6.25 & 5.52 & 13.22 & 0.30 & 0.34 \\
& $\mathrm{~B}$ & 5.75 & 5.10 & 12.75 & 0.29 & 0.41 \\
& $\mathrm{C}$ & 8.04 & 7.10 & 13.24 & 0.26 & 0.28 \\
& $\mathrm{D}$ & 8.38 & 7.35 & 14.01 & 0.29 & 0.32 \\
& $\mathrm{E}$ & 6.01 & 5.26 & 14.26 & 0.23 & 0.27 \\
\hline & Average & 6.89 & 6.07 & 13.5 & 0.27 & 0.32 \\
& $\begin{array}{c}\text { Standard } \\
\text { deviation }\end{array}$ & 1.23 & 1.07 & 0.62 & 0.03 & 0.06 \\
\hline
\end{tabular}

\section{Discussions}

The main constants were determined, although the values are scattered like any other characteristic of the biomaterial. The specific heat of the shell and marrow is higher than that of wood, yet the product $\rho \mathrm{CP}$ is close to that of heavy wood which allows providing a high specific heat with low thermal conductivity. Thus, the material can store heat, or it can be stored for release at the appropriate time. This is probably thanks to this property as raffia bamboo is the main material used to build the drying attic and the garret for conservation of dry products in our region. The transverse thermal conductivity of the shell is close to that of wood ranging from 0.12 to 0.23 for an average of 0.15 , but that of the marrow is estimated at 0.046 less than 0.065 which is the higher limit of this property in the insulation [22]. Their transverse average thermal diffusivities are, respectively, $1.96 \times 10^{-8}$ for the marrow and $2.35 \times 10^{-8}$ for the shell, while the timber is approximately $4.5 \times 10^{-7}$ [22].

The thermal constants vary slightly from one sample to another. The thermal conductivity of the shell in the direction perpendicular to the fiber is close to that of light wood $(\lambda=0.12 \mathrm{~W} / \mathrm{m} \cdot \mathrm{K})$, which is a good thermal insulator and 
TABLE 6: Global thermal properties dry raffia bamboo.

\begin{tabular}{|c|c|c|c|c|c|}
\hline & Specimen & $C_{a}(\mathrm{~J} / \mathrm{kg} \cdot \mathrm{K})$ & $\lambda_{a}(\mathrm{~W} / \mathrm{m} \cdot \mathrm{K})$ & $\alpha_{a} \times 10^{-8}\left(\mathrm{~m}^{2} / \mathrm{s}\right)$ & $E_{f a}\left(\mathrm{~J} \cdot \mathrm{s}^{1 / 2} / \mathrm{K} \cdot \mathrm{m}^{2}\right)$ \\
\hline \multirow{7}{*}{ Raffia bamboo } & A & 11759.5 & 0.07 & 2.08 & 507.5 \\
\hline & B & 13737.0 & 0.07 & 1.78 & 531.8 \\
\hline & $\mathrm{C}$ & 7750.5 & 0.07 & 3.28 & 364.78 \\
\hline & $\mathrm{D}$ & 7829.4 & 0.07 & 3.13 & 401.5 \\
\hline & $\mathrm{E}$ & 9706.7 & 0.06 & 2.69 & 366.0 \\
\hline & Average & 10156.6 & 0.07 & 2.59 & 434.3 \\
\hline & Standard deviation & 2588.3 & 0.005 & 6.50 & 79.78 \\
\hline
\end{tabular}
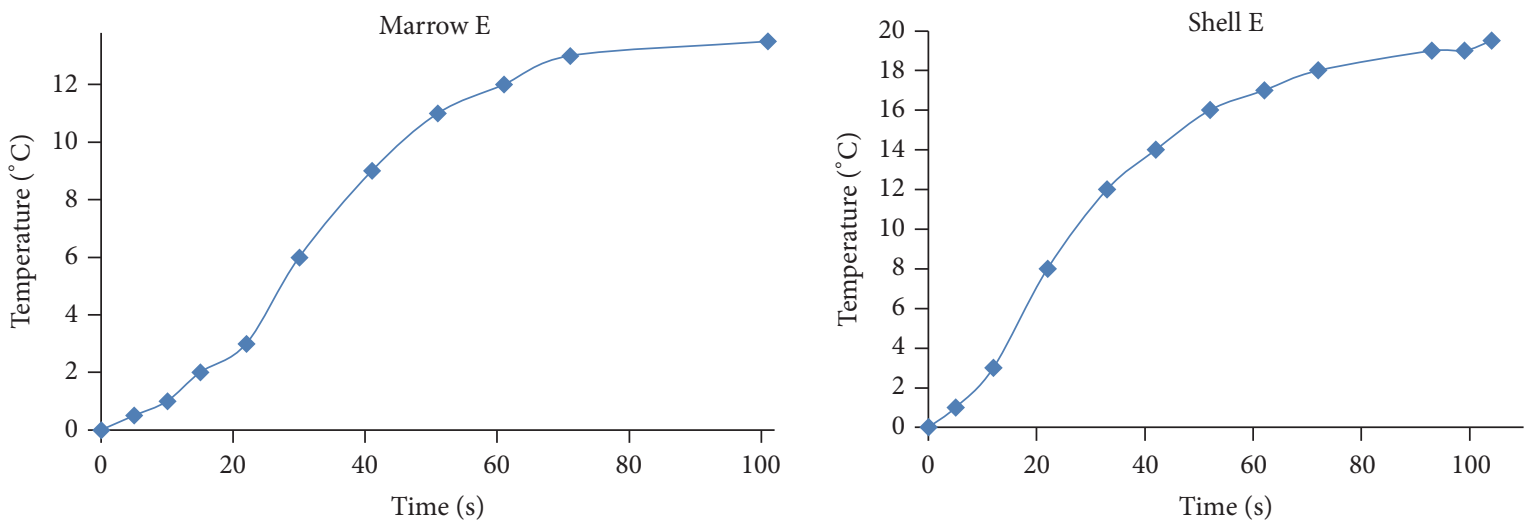

FIgURE 8: Experimental thermogram of a point in the plane located $2 \mathrm{~mm}$ from the surface irradiated (B).
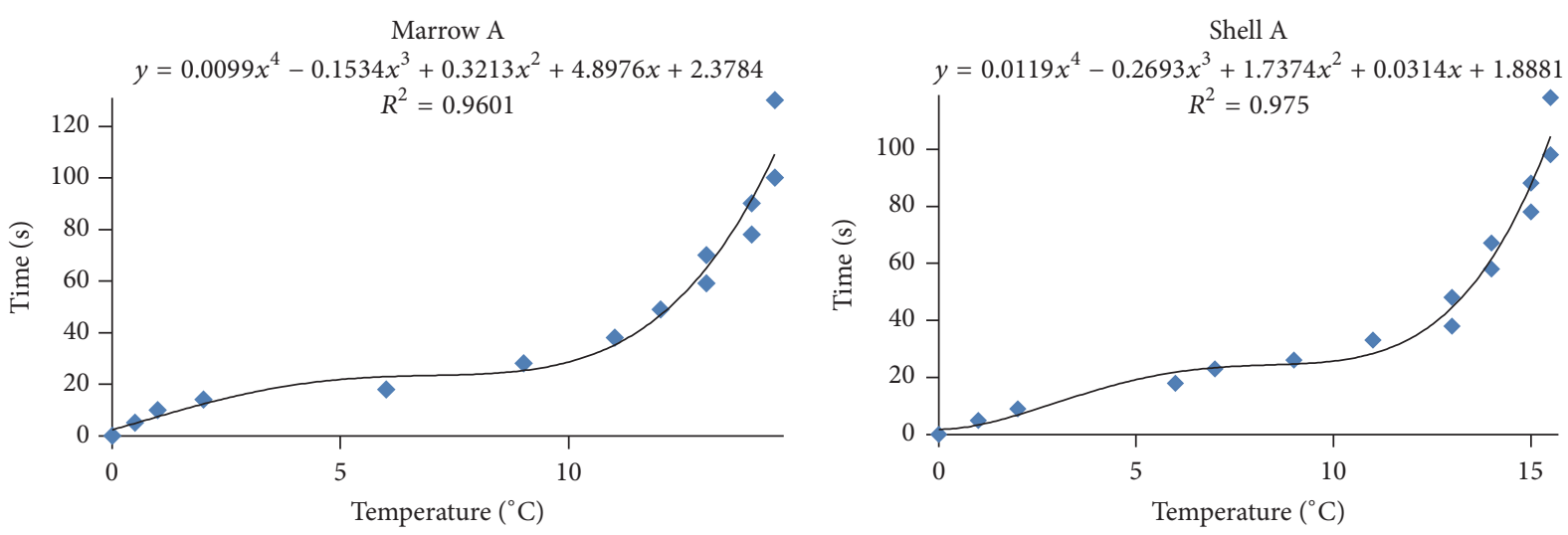

FIGURE 9: Correlation between changes in terms of temperature located $2 \mathrm{~mm}$ from the irradiated surface and the heat diffusion length.

that of the marrow is smaller and close to $0.04 \mathrm{~W} / \mathrm{m} \cdot \mathrm{K}$, characterizing wool and expanded polystyrene to be more insulating than wood [23].

An evaluation of the overall transverse thermal conductivity of anhydrous raffia bamboo gives an average of $0.07 \mathrm{~W} / \mathrm{m} \cdot \mathrm{K}$, smaller than that of the timber. We can justify this aspect by the fact that the raffia bamboo is more porous than wood [24]. Given the above results, we can say that the raffia bamboo is a very good thermal insulator.

\section{Conclusion}

The experimental study focused on the thermal properties of raffia bamboo and gives results which confirm its effectiveness as an insulation material having good heat storage capacity. It is probably this energy storage capacity that makes this bamboo building material for drying garrets, for henhouse, and for conservation of dry products in our region. From the results, raffia bamboo must be used as 

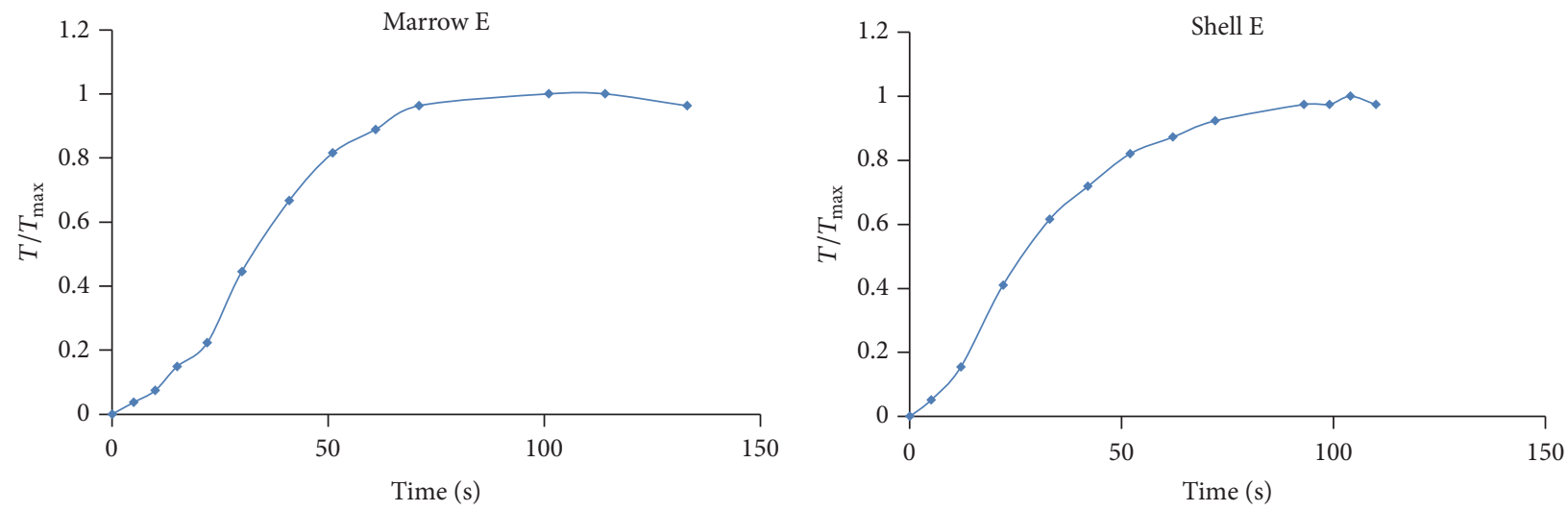

FIgure 10: Curve $T / T_{\max }$ with respect to time of the analytical model of Parker and Degiovanni.

thermal insulation material in the structures mentioned in the introduction (houses, drying lofts, and ceilings).

\section{Competing Interests}

The authors declare that there is no conflict of interests regarding the publication of this paper.

\section{References}

[1] N. P. Shiembo, Development and utilization of minor forest products in Cameroon with particular reference to raffia (Raphia spp.) and cane (Rattan palms) [M.Phil Thesis], Department of Forestry, University of Ibadan, Ibadan, Nigeria, 1986.

[2] J. K. Tangka, Raphia palm (Raphia taedigera) as structural material in the North West province of Cameroon [Master of science seminar], Department of Agricultural Engineering University of Ibadan, Ibadan, Nigeria, 2001.

[3] V. Ingram, J. C. Tieguhong, E. M. Nkamgnia, J. P. Eyebe, and M. Npawe, Bamboo Production to Consumption System, Cameroon, CIFOR (Center for International Forestry Research), Bogor, Indonesia, 2010.

[4] J. K. Tangka, B. Ndongo, and M. Onabid, "Raffia as a structural material in the grassland region of Cameroon," African Journal of Building Materials, vol. 5, no. 1, pp. 10-18, 2001.

[5] E. Foadieng, P. K. Talla, F. B. Pelap, M. Fogue, S. T. Mabekou, and A. F. Et Sinju, "Contribution à l'étude de l'anatomie et des proprieties physiques du bamboo de raphia vinifera (arecaceae)," Revue Scientifique et Technique Forêt et Environnement $d u$ Bassin du Congo (RIFFEAC), vol. 3, pp. 9-18, 2014.

[6] H. Urakami and M. Fukuyama, "The influence of specific gravity on thermal conductivity of wood," Bulletin of the Kyoto Prefect University for 25, 1981 (Japanese).

[7] D. L. Lang, "A quick thermal conductivity test on insulating materials," ASTM Bulletin 216, 1956.

[8] S. E. Gustafsson, E. Karawacki, and M. N. Khan, "Determination of the thermal-conductivity tensor and the heat capacity of insulating solids with the transient hot-strip method," Journal of Applied Physics, vol. 52, no. 4, pp. 2596-2600, 1981.

[9] P. R. Pradhan, K. Sachder, K. Bala, N. S. Saxena, and M. P. Sacksena, "Temperature dependence of thermal conductivity an thermal diffusivity of somme composites using the transient plane source technique," International Journal of Energy Research, vol. 13, pp. 411-417, 1991.
[10] Hladik, Métrologie des Propriétés Thérmophysiques des Matériaux, édition MASSON, 1990.

[11] M. Babacar Samba, Étude du Champ Thermique dans une Plaque: Application a la Mesure de la Conductivité Thermique des Matériaux, Projet de fin d'études en vue de l'obtention du diplôme d'ingénieur de conception, Ecole Supérieure Polytechnique, Centre de Thiès, département du Génie Mécanique, Thiès, Senegal, 2005.

[12] T. Harada, "Thermal constants of wood during the heating process measured with the laser flash method," Journal of Wood Science, vol. 44, no. 6, pp. 425-431, 1998.

[13] M. Mohamed Filali, Conductivité thermique apparente des milieux granulaires soumis à des contraintes mécaniques: modélisation et mesures [Ph.D. thesis], Institut National Polytechnique de Toulouse, École Doctorale TYFEP, Paris, France, 2006.

[14] M. Gustavsson, E. Karawacki, and S. E. Gustafsson, "Thermal conductivity, thermal diffusivity, and specific heat of thin samples from transient measurements with hot disk sensors," Review of Scientific Instruments, vol. 65, no. 12, pp. 3856-3859, 1994.

[15] M. Devisme, Conductivité et diffusivité thermiques simultanées par mesure de flux en régime non stationnaire [Ph.D. thesis], 1973.

[16] le. Maréchal and 1. M. Devisme, Mesure rapide et simultanée de la conductivité et de la diffusivité thermique, Entropie, no. 64, 1975.

[17] W. J. Parker, R. J. Jenkins, C. P. Butler, and G. L. Abbott, "Flash method of determining thermal diffusivity, heat capacity, and thermal conductivity," Journal of Applied Physics, vol. 32, no. 9, pp. 1679-1684, 1961.

[18] A. Degiovanni, "Diffusivité et méthode Flash," Revue Générale de Thermique Française 185, 1977.

[19] C. Langlais and J. Boulant, "Use of a two heat flow transducer apparatus for transient thermal measurements on porous insulating materials," in Proceedings of the ASTM Symposium, Bal Harbour, Fla, USA, 1987.

[20] Astm STP 885, "Building applications of heat flux transducers", 1985.

[21] J. P. Cull, "Thermal conductivity probes for rapid measurements in rock," Journal of Physics E: Scientific Instruments, vol. 7, no. 9, pp. 771-774, 1974.

[22] P. Sallenave, Propriétés Physiques et Mécaniques des Bois Tropicaux de l'Union Française, Centre technique forestier tropical (CTFT), Nogent-sur-Marne, France, 1955. 
[23] J. Natterer, J. L. Sandoz, M. Rey, and M. Fiaux, Construction en Bois, Matériau, Technologie et Dimensionnement, vol. 13 of Traité de Génie Civil de l'Ecole Polytechnique Fédérale de Lausanne, Deuxième édition Revue et Augmentée, Presses Polytechniques et Universitaires Romandes, CH-1015 Lausannes, 2004.

[24] CERTU/CETE de Lyon, Confort Thermique pour Chargé d'Opération de Construction Publique, Momento Thechnique du Bâtiment, Lyon, France, 2003. 

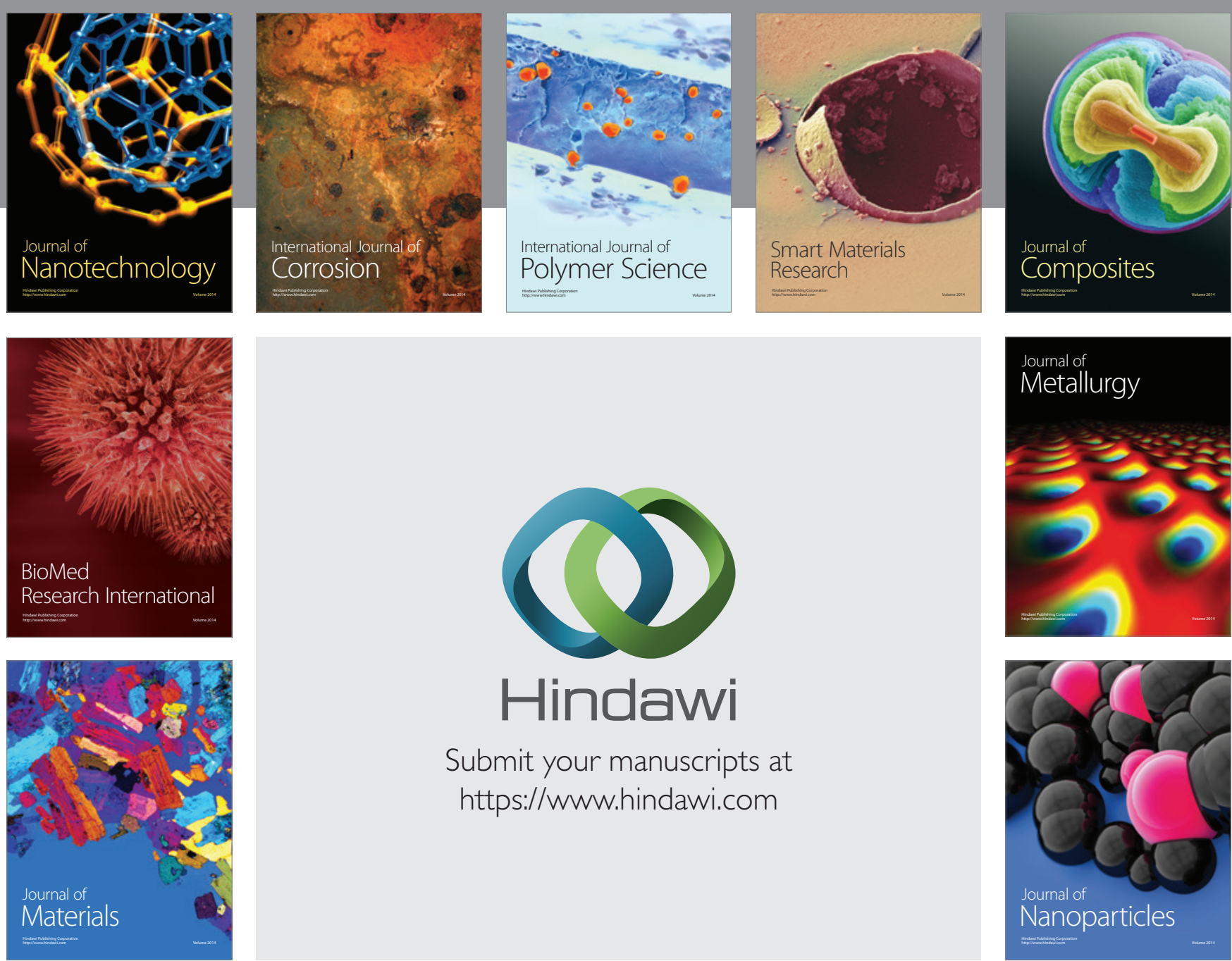

\section{Hindawi}

Submit your manuscripts at

https://www.hindawi.com

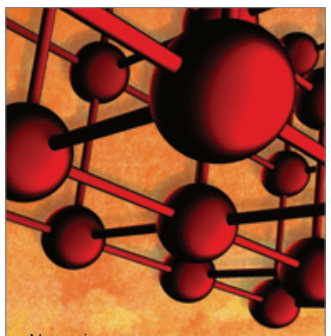

Materials Science and Engineering
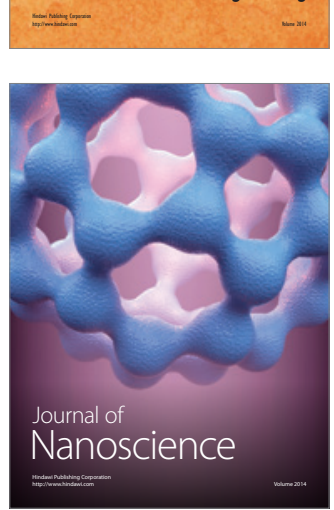
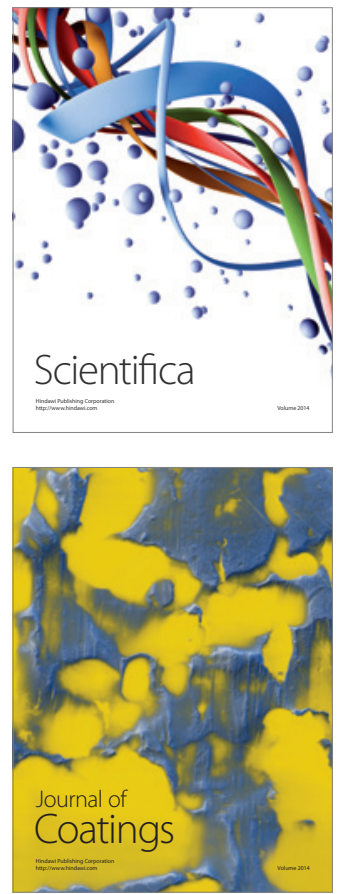
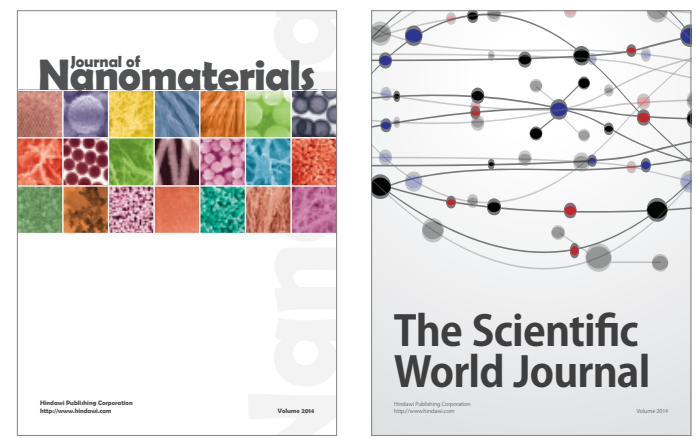

The Scientific World Journal
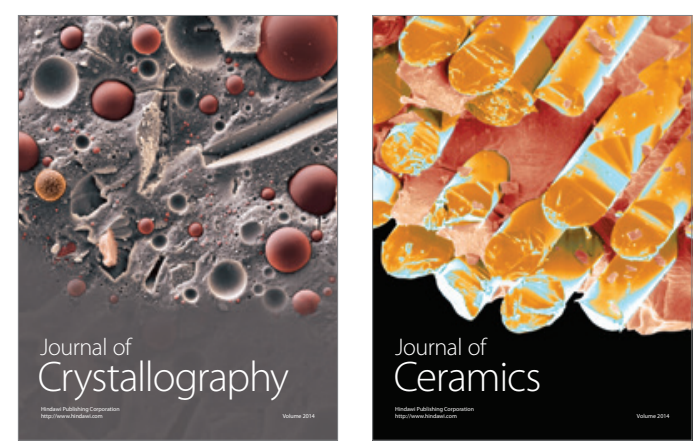
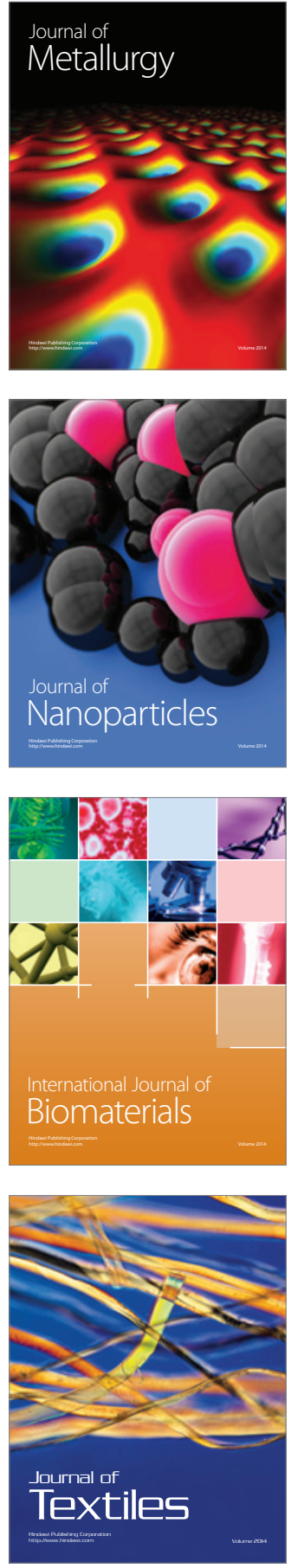